\title{
COPD in primary lung cancer patients: prevalence and mortality
}

\author{
This article was published in the following Dove Press journal: \\ International Journal of COPD \\ 23 March 2016 \\ Number of times this article has been viewed
}

\section{Elinor Ytterstad' \\ Per C Moe ${ }^{2}$ \\ Audhild Hjalmarsen ${ }^{3}$ \\ 'Department of Mathematics and Statistics, UiT The Arctic University of Norway, ${ }^{2}$ Department of Pulmonary Medicine, University Hospital of North Norway, ${ }^{3}$ Department of Clinical Medicine, UiT The Arctic University of Norway, Tromsø, Norway}

Background: Previous studies have relied on international spirometry criteria to diagnose COPD in patients with lung cancer without considering the effect lung cancer might have on spirometric results. The aim of this study was to examine the prevalence of COPD and emphysema at the time of primary lung cancer diagnosis and to examine factors associated with survival.

Materials and methods: Medical records, pulmonary function tests, and computed tomography scans were used to determine the presence of COPD and emphysema in patients diagnosed with primary lung cancer at the University Hospital of North Norway in 2008-2010.

Results: Among the 174 lung cancer patients, 69\% had COPD or emphysema (39\% with COPD, 59\% with emphysema; male:female ratio 101:73). Neither COPD nor emphysema were significantly associated with lung cancer mortality, whereas patients with non-small-cell lung cancer other than adenocarcinoma and squamous cell carcinoma had a risk of lung cancer mortality that was more than four times higher than that of patients with small-cell lung cancer (hazard ratio [HR] 4.19, 95\% confidence interval [CI] 1.56-11.25). Females had a lower risk of lung cancer mortality than males (HR $0.63,95 \%$ CI $0.42-0.94$ ), and patients aged $\geq 75$ years had a risk that was twice that of patients aged $<75$ years (HR 2.48, 95\% CI 1.59-3.87). Low partial arterial oxygen pressure (4.0-8.4 kPa) increased the risk of lung cancer mortality (HR 2.26, 95\% CI 1.29-3.96). So did low partial arterial carbon dioxide pressure (3.0-4.9 kPa) among stage IV lung cancer patients (HR 2.23, 95\% CI 1.29-3.85). Several patients with respiratory failure had previously been diagnosed with COPD.

Conclusion: The observed prevalence of COPD was lower than that in previous studies. Neither COPD nor emphysema were significantly associated with lung cancer mortality.

Keywords: lung cancer, COPD, emphysema, computed tomography

\section{Introduction}

Lung cancer is the leading cause of cancer death worldwide, accounting for more than a million deaths annually., ${ }^{1,2}$ A Canadian study using life-table methodology found that 172 in 1,000 males and 116 in 1,000 females who currently smoke will eventually develop lung cancer, in addition to 13 in 1,000 male and 14 in 1,000 female nonsmokers. ${ }^{3}$ Another study reported that $16 \%$ of male and $10 \%$ of female cigarette smokers die of lung cancer. ${ }^{4}$ Overall 5-year lung cancer survival is poor, at approximately $15 \%$.,

COPD is characterized by airflow obstruction in the lungs and symptoms related to decreased expiratory volume. ${ }^{7}$ One study reported that about $26 \%$ of heavy smokers develop clinically significant COPD. ${ }^{8}$ Another study reported that COPD affects $15 \%-20 \%$ of smokers and $50 \%-80 \%$ of lung cancer patients with a substantial smoking history. ${ }^{9}$ Indeed, $40 \%-70 \%$ of lung cancer patients also have COPD, and the risk of COPD is sixfold higher in lung cancer patients than in matched smokers, leading to the
Department of Mathematics and

Statistics, UiT The Arctic University of

Norway, Hansine Hansens veg 54, 9037

Tromsø, Norway

Tel +47 77644015

Email elinor.ytterstad@uit.no
International Journal of COPD 2016:1 | 625-636

Dovepress

http://dx.doi.org/10.2147/COPD.S101183 (c) (1) (5) 2016 Ytterstad et al. This work is published and licensed by Dove Medical Press Limited. The full terms of this license are available at https://www.dovepress.com/terms.php cc) and incorporate the Creative Commons Attribution - Non Commercial (unported, v3.0) License (http://creativecommons.org/licenses/by-nc/3.0/). By accessing the work you hereby accept the Terms. Non-commercial uses of the work are permitted without any further permission from Dove Medical Press Limited, provided the work is properly attributed. For permission for commercial use of this work, please see paragraphs 4.2 and 5 of our Terms (https://www.dovepress.com/terms.php). 
conclusion that COPD and lung cancer must share risk factors other than tobacco exposure. ${ }^{10-14}$ Such factors as airflow limitation, smoking, and genotype can predispose a person to COPD and lung cancer, ${ }^{10}$ and smokers have a host susceptibility to both these diseases..$^{4,8,9,15}$ However, the association between COPD and lung cancer is largely explained by smoking habits and the timing of COPD diagnosis. Powell et al reported that $23 \%$ of lung cancer cases had a prior diagnosis of COPD, compared with only $6 \%$ of controls. ${ }^{16}$

Pulmonary emphysema is defined morphologically as the enlargement of air spaces distal to the terminal bronchiole, due to dilatation or destruction of alveolar walls. ${ }^{7,17}$ Computed tomography (CT)-detected emphysema has been shown to be associated with an increased risk of lung cancer, ${ }^{15,18-20}$ and even nonsmokers with emphysema have an elevated risk of lung cancer. ${ }^{12,13}$

Inflammatory processes may also play a central role in carcinogenesis, ${ }^{11}$ and COPD and emphysema are major causes of inflammation in lung tissue. ${ }^{12}$ However, precise details of the relationship between COPD, emphysema, and lung cancer remain uncertain. Whether airflow obstruction predisposes to lung cancer or whether both arise from a common factor is unclear and beyond the scope of this study. ${ }^{6}$

Previous studies either relied on international spirometry criteria to diagnose COPD in patients with lung cancer without considering the effect lung cancer might have on the spirometric results or used variable spirometric criteria for pulmonary function testing (PFT) that did not conform to revised standard guidelines. The aim of this study was to examine the prevalence of COPD and emphysema at the time of primary lung cancer diagnosis using a combination of medical records, PFT (including spirometry and blood gases), and CT scans of the lungs. We also examined factors associated with lung cancer mortality.

\section{Materials and methods Data}

We retrospectively reviewed the medical records of the 174 patients (101 males and 73 females between 31 and 90 years of age) diagnosed with primary lung cancer from 2008 to 2010 at the University Hospital of North Norway. Information on age, sex, smoking status, body mass index (BMI), lung cancer diagnosis, histologic type, tumor size, and cancer stage was taken from medical records, as were PFT results like spirometry (forced vital capacity [FVC] and forced expiratory volume in 1 second $\left[\mathrm{FEV}_{1}\right]$ ), arterial blood gases (partial arterial oxygen pressure $\left[\mathrm{PaO}_{2}\right], \mathrm{PaCO}_{2}$, and carboxyhemoglobin [COHb] in arterial blood plasma), and CT scans of the lungs. Smoking status was recorded as only two categories: nonsmoker and smoker/ex-smoker. An anonymized version of the data set is available in Table S1. The study was approved by the Regional Committee of Research Ethics of North Norway. Patient consent was not obtained as this is a retrospective study.

\section{Lung cancer}

Histologic lung cancer was categorized as small-cell lung cancer (SCLC) and non-SCLC (NSCLC). NSCLC was then further categorized as adenocarcinoma, squamous cell carcinoma (SCC), or other, which consisted primarily of large-cell carcinoma and undifferentiated carcinoma of the lungs. Patients with bronchial carcinoids were excluded. Cancer stage was recorded using the TNM classification and the staging $\mathrm{I}-\mathrm{IV} .{ }^{21-24}$

\section{Assessment of COPD}

Spirometry values at lung cancer diagnosis (Jaeger MasterScreen PFT; BD, Franklin Lakes, NJ, USA) were recorded using European reference values. FVC and $\mathrm{FEV}_{1}$ were recorded in medical records in liters and percentage predicted values, as well as $\mathrm{FEV}_{1} / \mathrm{FVC} \%$. The GOLD (Global initiative for chronic Obstructive Lung Disease) criteria were used to assign a grade of clinical severity to COPD based on $\mathrm{FEV}_{1}$ and $\mathrm{FEV}_{1} / \mathrm{FVC}^{\circ}:^{7}$ patients with an $\mathrm{FEV}_{1} / \mathrm{FVC}$ ratio $\leq 70 \%$ were classified as having COPD in all grades; grade 1 was defined as having an $\mathrm{FEV}_{1} \geq 80 \%$; grade 2 as $50 \% \leq \mathrm{FEV}_{1}<80 \%$; grade 3 as $30 \% \leq \mathrm{FEV}_{1}<50 \%$; and grade 4 as $\mathrm{FEV}_{1}<30 \%$.

Patients were classified as having COPD at lung cancer diagnosis if they had a previous spirometric diagnosis of COPD in their medical records (known COPD), or if they fulfilled the spirometric criteria, including the authentic flowvolume curve seen in obstructive lung disease (undiagnosed COPD). Patients with bronchial asthma and a normal PFT shortly before lung cancer diagnosis were classified as not having COPD (no COPD), as were patients with an obvious explanation for their spirometric findings, such as a central tumor or atelectasis. Patients with missing data were categorized as "missing - spirometry".

\section{Assessment of emphysema}

The presence of emphysema at lung cancer diagnosis was determined based on information from CT scans (Sensation 16; Siemens AG, Munich, Germany) contained in medical records. All CT scans were reviewed at diagnosis by one radiologist and two pulmonologists, using previously 
published methods. When emphysema was detected visually in the CT scan (ie, with a score $\geq 1$ ), the patient was classified as having emphysema. ${ }^{15,25,26}$

\section{Statistical analysis}

Survival times were recorded in days from diagnosis of lung cancer, and were analyzed using the Cox proportional hazard model. Each patient was followed from the date of lung cancer diagnosis until death from primary lung cancer or the end of the study period (October 1, 2014), whichever came first. The following variables were also recorded at diagnosis and considered time-independent covariates in the Cox model: age, sex, smoking status, BMI, histologic type, tumor size, cancer stage, $\mathrm{COPD}, \mathrm{PaO}_{2}, \mathrm{PaCO}_{2}, \mathrm{COHb}$, and emphysema.

Preliminary analyses were performed on subsets of the data, in order to identify possible interactions between covariates. The only significant interaction was between cancer stage and $\mathrm{PaCO}_{2}$. As part of the preliminary analyses, we categorized age into four groups: 31-64, 65-69, 70-74, and 75-90 years. The three youngest age-groups were found to have an equal effect on lung cancer mortality, and age was thus reduced to a dichotomous variable (31-74 and 75-90 years). $\mathrm{PaO}_{2}$ was divided into three categories (4-8.4, 8.5-9.9, and $\geq 10 \mathrm{kPa})$, as was $\mathrm{PaCO}_{2}(3-4.9,5-5.9$, and $6-10 \mathrm{kPa})$.

It is common to include cancer stage as a categorical covariate in a Cox proportional hazard regression model, but this must be done with care, because a mixture of individuals with cancer stages ranging from I to IV may give rise to nonproportionality in hazard ratios (HRs). This phenomenon is thoroughly discussed in the literature. ${ }^{27}$ We tested proportionality, and did not find any significant violations of the proportional hazard assumption. Another possible feature of the covariate cancer stage is heterogeneity within each stage, where some individuals have a more seriously developed cancer than others within the same stage. Such heterogeneity can be modeled as a frailty covariate. ${ }^{27}$ We considered this in the preliminary analyses, and found only minor changes in the coefficient estimates compared to a model without frailty.

In addition to the traditional Cox model, we modeled the data as a randomized Wiener process ${ }^{27}$ to identify whether a covariate was of one of two types: 1) a measure of how far the cancer had advanced; or 2) a causal influence on the development of the disease.

Results are reported as HRs with $95 \%$ confidence intervals (CIs), and $P$-values are given. Calculations were performed in the statistical computing language $\mathrm{R}^{28}$ using the R package Survival. ${ }^{29}$ A test for violation of the proportional hazard assumption in the Cox model was performed with the R-routine cox.zph ${ }^{29}$ in the Survival package. For the Wiener process, we used the R package "invGauss". ${ }^{30}$

\section{Results}

Of the 174 patients, 120 (69\%) had COPD and/or emphysema (67 [38.5\%] with COPD and 102 [58.6\%] with emphysema). Of the 67 patients with COPD, only 18 (26.9\%) did not have coexisting emphysema. The male:female ratios were 101 (58\%):73 (42\%) for all patients, 40 (59.7\%):27 (40.3\%) for patients with COPD, and 65 (63.7\%):37 (36.3\%) for patients with emphysema (Table 1). Of all the patients, 138 $(80 \%)$ had stage III-IV lung cancer at the time of diagnosis. Only eight $(23 \%)$ of the 35 patients with stage I-II lung cancer had neither COPD nor emphysema (Table 1). Of the 18 patients with COPD without concomitant emphysema, all but two had stage III-IV lung cancer (data not shown). Only five patients were nonsmokers, and two had missing data on smoking status (data not shown).

Six patients had missing histologic type, and were excluded from the analyses. Of the remaining 168 patients, $27 \%$ were diagnosed with SCLC, $37 \%$ with adenocarcinoma, $32 \%$ with SCC, and $4 \%$ with other - NSCLC (Figure 1). We further excluded 23 patients with missing data on at least one of the significant factors for lung cancer mortality: one patient with missing cancer stage, and 22 patients with missing $\mathrm{PaO}_{2} / \mathrm{PaCO}_{2}$ values. Finally, we excluded one male patient with missing PFT who had a strong influence on the Cox-model estimates. Therefore, the final analyses included 144 patients.

Smoking status, $\mathrm{BMI}$, tumor size, $\mathrm{COHb}$, and emphysema were not significant covariates in the Cox model. The risk of lung cancer mortality was not significantly different for known-COPD/undiagnosed-COPD patients compared to no-COPD patients, and missing-spirometry patients had a significantly higher risk of lung cancer mortality (HR 6.33, 95\% CI 2.69-14.93). The randomized Wiener process identified missing-spirometry patients as a group with more advanced cancer. In a separate analysis, we also categorized COPD into the four GOLD grades, ${ }^{7}$ but found no significant differences in survival between these grades of COPD (data not shown).

Among the histologic types, other-NSCLC patients had a risk of lung cancer mortality that was four times higher than that of SCLC patients (HR 4.19, 95\% CI 1.56-11.25). 
Table I Baseline characteristics, means, and standard deviation of lung cancer patients diagnosed at the University Hospital of North Norway in 2008-2010 ( $n=174)$ according to presence of COPD and emphysema

\begin{tabular}{|c|c|c|c|c|c|c|c|c|}
\hline \multirow{2}{*}{$\begin{array}{l}\text { Patient group } \\
\mathrm{n}\end{array}$} & \multicolumn{2}{|l|}{ All } & \multicolumn{2}{|l|}{ COPD } & \multicolumn{2}{|c|}{$\begin{array}{l}\text { Emphysema } \\
\text { without COPD }\end{array}$} & \multicolumn{2}{|c|}{$\begin{array}{l}\text { Neither COPD } \\
\text { nor emphysema }\end{array}$} \\
\hline & 174 & & 67 & & 53 & & 54 & \\
\hline$\%$ male & 58 & & 59.7 & & 66 & & 48.1 & \\
\hline n, cancer stage I + II & 35 & & 16 & & II & & 8 & \\
\hline \multirow[t]{2}{*}{$\mathrm{n}$, cancer stage III + IV } & 138 & & 51 & & 42 & & 45 & \\
\hline & Mean & SD & Mean & SD & Mean & SD & Mean & SD \\
\hline Age (years), n=174 & 67.92 & 10.17 & 70.73 & 8.52 & 67.58 & 9.47 & 64.76 & 11.80 \\
\hline BMI $\left(\mathrm{kg} / \mathrm{m}^{2}\right), \mathrm{n}=\mathrm{I} 55$ & 24.97 & 5.01 & 25.31 & 5.23 & 23.35 & 4.47 & 25.93 & 4.92 \\
\hline $\mathrm{FVC}(\mathrm{L}), \mathrm{n}=\mathrm{I} 44$ & 2.62 & 0.84 & 2.40 & 0.75 & 2.74 & 0.94 & 2.81 & 0.81 \\
\hline FVC (\%) predicted & 78.70 & 20.21 & 73.38 & 17.29 & 80.56 & 22.52 & 84.43 & 20.40 \\
\hline $\mathrm{FEV}_{1}(\mathrm{~L}), \mathrm{n}=144$ & 1.83 & 0.67 & 1.48 & 0.50 & 1.99 & 0.65 & 2.18 & 0.67 \\
\hline $\mathrm{FEV}_{1}(\%)$ predicted & 69.05 & 21.08 & 57.50 & 16.75 & 74.59 & 20.87 & 80.41 & 18.77 \\
\hline $\mathrm{FEV}_{1} / \mathrm{FVC}(\%), \mathrm{n}=144$ & 70.17 & 12.68 & 62.46 & 12.05 & 73.85 & 11.15 & 77.61 & 8.29 \\
\hline $\mathrm{PaO}_{2}(\mathrm{kPa}$, air $), \mathrm{n}=151$ & 9.93 & 1.58 & 9.56 & 1.34 & 9.70 & 1.56 & 10.65 & 1.68 \\
\hline $\mathrm{PaCO}_{2}(\mathrm{kPa}$, air $), \mathrm{n}=|5|$ & 5.10 & 0.68 & 5.22 & 0.57 & 5.14 & 0.86 & 4.89 & 0.62 \\
\hline $\mathrm{COHb}(\%), \mathrm{n}=\mathrm{I} 44$ & 1.49 & 1.12 & 1.40 & 0.82 & 1.68 & 1.40 & 1.44 & 1.21 \\
\hline \multicolumn{9}{|l|}{ Tumor size $(\mathrm{cm})$} \\
\hline All patients, $n=167$ & 5.13 & 2.46 & 5.32 & 2.55 & 5.27 & 2.69 & 4.73 & 2.04 \\
\hline Females, $n=68$ & 4.73 & 2.26 & 4.84 & 2.16 & 4.64 & 2.68 & 4.67 & 2.12 \\
\hline
\end{tabular}

Abbreviations: $\mathrm{BMI}$, body mass index; $\mathrm{FVC}$, forced vital capacity; $\mathrm{FEV}_{1}$, forced expiratory volume in I second; $\mathrm{PaO}_{2}$, partial arterial oxygen pressure; $\mathrm{COHb}$, carboxyhemoglobin (in arterial blood plasma); $\mathrm{PaCO}_{2}$, partial arterial carbon dioxide pressure.

The Wiener process identified other - NSCLC as having poorer survival, meaning a more advanced cancer. The risk of lung cancer mortality among patients with adenocarcinoma and SCC was not significantly different from that of SCLC patients (Table 2).
We found a weak but significant effect of sex on lung cancer mortality, with females showing a lower risk than males (HR 0.63, 95\% CI 0.42-0.94). In contrast, advanced age was found to increase the risk of lung cancer mortality (Table 2). Further results from the Cox model showed that

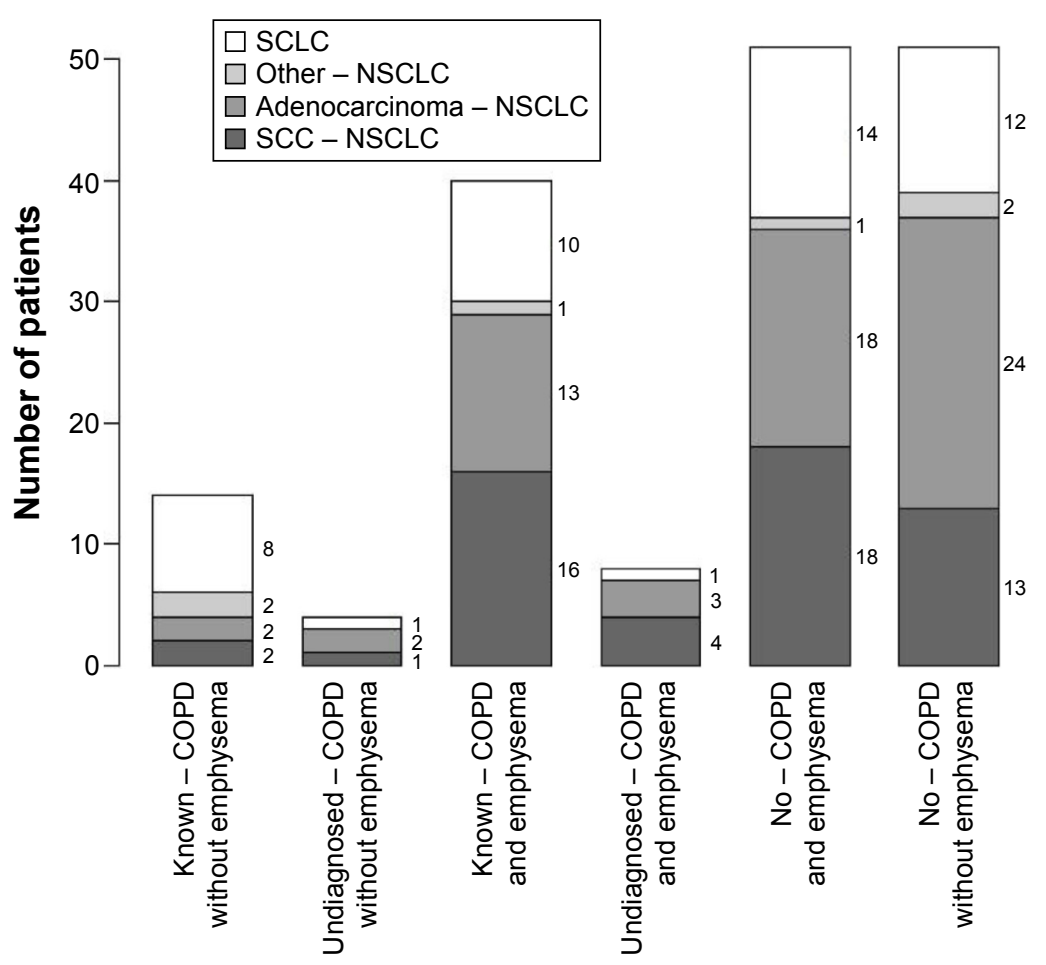

Figure I Prevalence of COPD and emphysema by histologic type of primary lung cancer $(n=168)$.

Abbreviations: NSCLC, non-small-cell lung cancer; SCC, squamous cell carcinoma; SCLC, small-cell lung cancer. 
Table 2 Impact of evaluated variables on survival of patients with primary lung cancer according to Cox regression analysis ( $\mathrm{n}=\mathrm{I44)}$

\begin{tabular}{|c|c|c|c|c|}
\hline Variables & Category & HR & $95 \% \mathrm{Cl}$ & $P$-value \\
\hline Age (reference $<75$ years) & $\geq 75$ years & 2.48 & $1.59-3.87$ & 0.0001 \\
\hline Sex & Female & 0.63 & $0.42-0.94$ & 0.0239 \\
\hline \multirow[t]{3}{*}{ COPD (reference no - COPD) } & Known-COPD & 1.02 & $0.65-1.60$ & 0.9388 \\
\hline & Undiagnosed - COPD & 1.02 & $0.47-2.23$ & 0.9609 \\
\hline & Missing - spirometry & 6.33 & $2.69-14.93$ & $<0.0001$ \\
\hline \multirow[t]{3}{*}{ Histologic type (reference SCLC) } & Adenocarcinoma - NSCLC & 1.30 & $0.78-2.15$ & 0.3157 \\
\hline & SCC - NSCLC & 0.99 & $0.57-1.7 \mid$ & 0.9679 \\
\hline & Other - NSCLC & 4.19 & $1.56-11.25$ & 0.0045 \\
\hline \multirow{2}{*}{$\mathrm{PaO}_{2}(\mathrm{kPa}$, air $)$, reference $\geq 10$} & $4.0-8.4$ & 2.26 & $1.29-3.96$ & 0.0045 \\
\hline & $8.5-9.9$ & 1.44 & $0.91-2.28$ & 0.1172 \\
\hline \multicolumn{5}{|l|}{$\mathrm{PaCO}_{2}(\mathrm{kPa}$, air), reference 5.0-5.9 } \\
\hline \multirow[t]{2}{*}{ Stage I } & $3-4.9$ & 1.69 & $0.31-9.34$ & 0.5456 \\
\hline & $6-10$ & 11.24 & $2.64-47.85$ & 0.0011 \\
\hline \multirow[t]{2}{*}{ Stage II } & $3-4.9$ & 1.70 & $0.47-6.21$ & 0.4226 \\
\hline & $6-10$ & 19.97 & $1.92-208.06$ & 0.0123 \\
\hline \multirow[t]{2}{*}{ Stage III } & $3-4.9$ & 1.58 & $0.77-3.22$ & 0.2096 \\
\hline & $6-10$ & 0.76 & $0.22-2.64$ & 0.6644 \\
\hline \multirow[t]{2}{*}{ Stage IV } & $3-4.9$ & 2.23 & $1.29-3.85$ & 0.0040 \\
\hline & $6-10$ & 0.28 & $0.07-1.06$ & 0.0611 \\
\hline
\end{tabular}

Note: Patients with missing data were categorized as "missing - spirometry".

Abbreviations: HR, hazard ratio; $\mathrm{Cl}$, confidence interval; NSCLC, non-small-cell lung cancer; SCC, squamous cell carcinoma; $\mathrm{PaO}_{2}$, partial arterial oxygen pressure; SCLC, small-cell lung cancer; $\mathrm{PaCO}_{2}$, partial arterial carbon dioxide pressure.

patients with a low $\mathrm{PaO}_{2}$ (4.0-8.4), compared to those with a high $\mathrm{PaO}_{2}(\geq 10)$, had an $\mathrm{HR}$ of 2.26 (95\% CI 1.29-3.96). Among the 28 patients with low $\mathrm{PaO}_{2}, 16$ were knownCOPD patients, while only five were no-COPD patients (data not shown). Among patients with stage IV lung cancer, having a low $\mathrm{PaCO}_{2}(3.0-4.9)$ increased the risk of lung cancer mortality (HR 2.23, 95\% CI 1.29-3.85). Among the 33 patients with stage IV lung cancer and a low $\mathrm{PaCO}_{2}$, there were 19 no-COPD patients and seven known-COPD patients (data not shown). The Wiener process showed that the effect of having stage IV lung cancer and a low
$\mathrm{PaCO}_{2}$ was due to the presence of advanced cancer at time of diagnosis.

Among patients below 75 years of age, 5-year survival with stage I lung cancer was $80 \%$ in females and $70 \%$ in males. Twoyear survival with stage III lung cancer was $60 \%$ in females and $45 \%$ in males (Figure 2). Patients (except those with other NSCLC) with missing spirometry showed the poorest 2-year survival with stage III lung cancer, at $6 \%$ or less, whereas 2-year survival among all other patients was $60 \%$ and $45 \%$ for young females and males, respectively, and $28 \%$ and $14 \%$ in females and males aged 75 years and older (Figure 3).

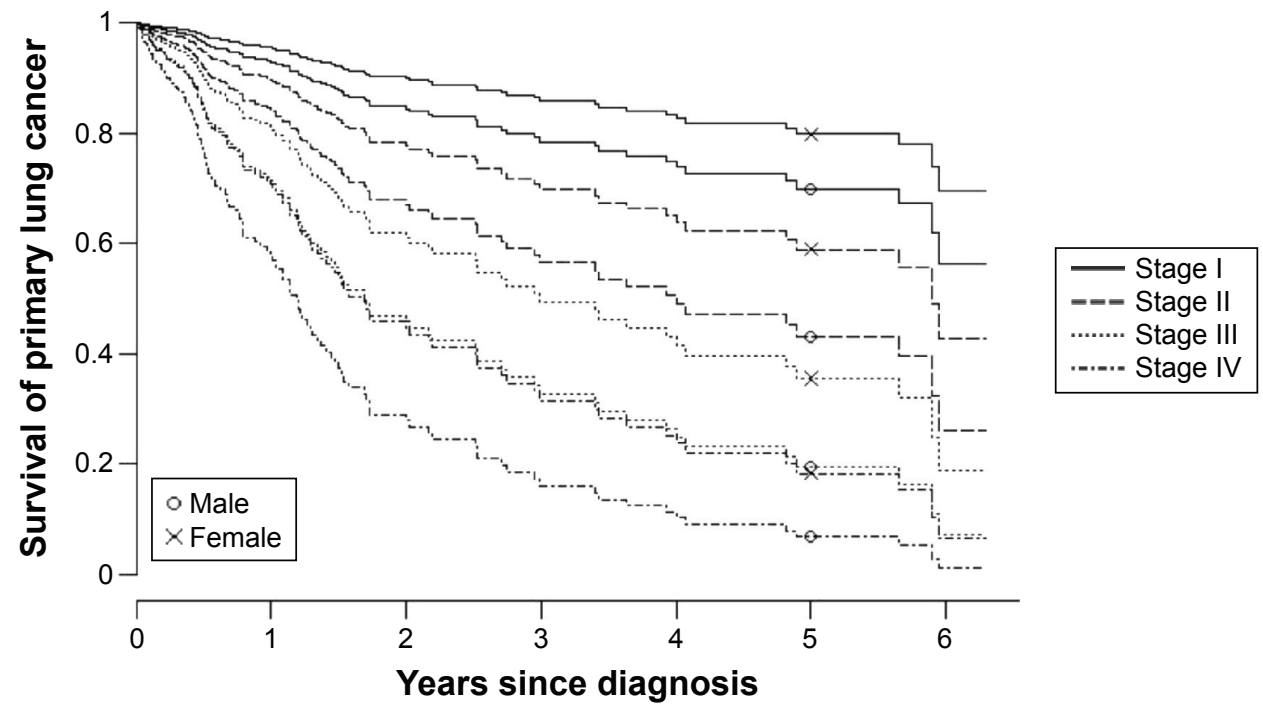

Figure 2 Survival curves for primary lung cancer (except other - NSCLC) by stage among males and females younger than 75 years. Note: $\mathrm{PaO}_{2}$ fixed at $\geq 10, \mathrm{PaCO}_{2}$ at $5.0-5.9 \mathrm{kPa}$.

Abbreviations: NSCLC, non-small-cell lung cancer; $\mathrm{PaO}_{2}$, partial arterial oxygen pressure; $\mathrm{PaCO}_{2}$, partial arterial carbon dioxide pressure. 


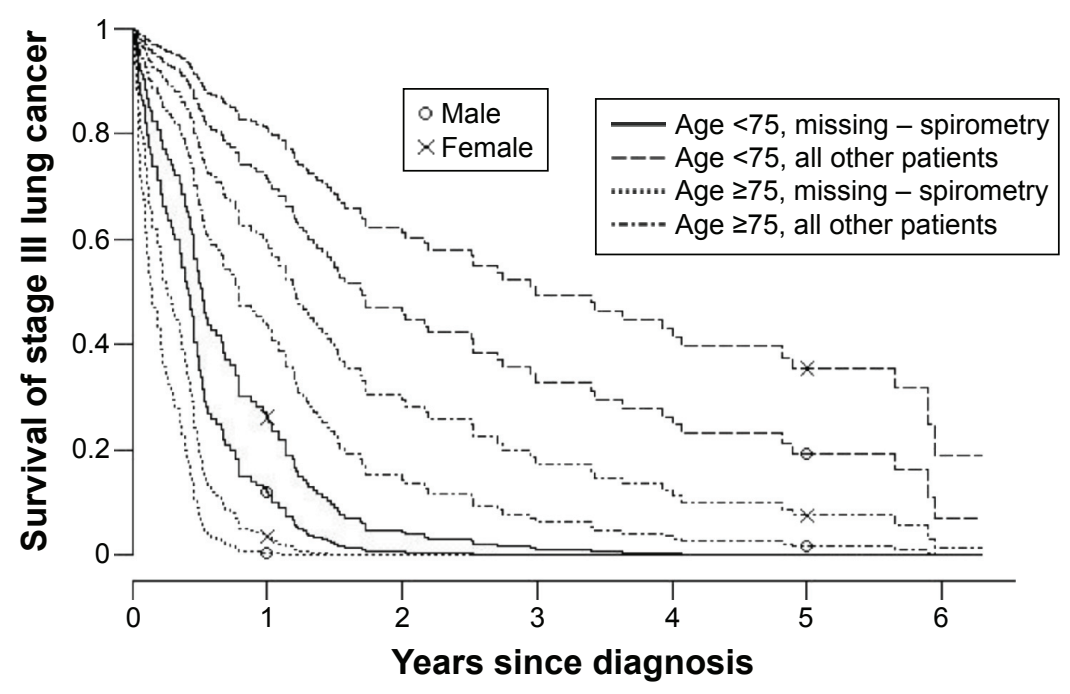

Figure 3 Survival curve for primary lung cancer (except other - NSCLC) stage III by age, sex, and spirometry.

Notes: $\mathrm{PaO}_{2}$ fixed at $\geq 10, \mathrm{PaCO}_{2}$ at 5.0-5.9 kPa. Patients with missing data were categorized as "missing - spirometry".

Abbreviations: NSCLC, non-small-cell lung cancer; $\mathrm{PaO}_{2}$, partial arterial oxygen pressure; $\mathrm{PaCO}_{2}$, partial arterial carbon dioxide pressure.

\section{Discussion}

About $80 \%$ of patients with primary lung cancer are diagnosed with stage III-IV cancer, ${ }^{1,2,5}$ which is consistent with our findings. However, whereas previous studies used history of sputum production and spirometry as diagnostic criteria for COPD, ${ }^{7,17,18,31}$ we chose to classify patients as having COPD if a diagnosis was present in their medical records, or if they had spirometric results, arterial blood-gas results, and visual detection of emphysema in their CT scan that indicated COPD. Patients with a central tumor with or without coexisting atelectasis as the only known cause of decreased $\mathrm{FEV}_{1}$ were categorized as not having COPD, thus reducing the possibility of overdiagnosis of COPD. We found a prevalence of COPD of $39 \%$, which is one of the lowest published so far. ${ }^{12,15,19,32}$ The prevalence of emphysema that we observed was similar to that in previous studies. ${ }^{15,19}$ In our study, all but two patients with COPD and no concomitant emphysema had stage III-IV lung cancer. However, it is important to note that emphysema may be less visible on the CT scans of patients with advanced lung cancer. Moreover, the PFT of patients with lung cancer may be lower, which can mask COPD or lead to misdiagnosis. ${ }^{15}$

This retrospective, descriptive study of patients with primary lung cancer included a 5-year survival study. We found that lung cancer patients with missing spirometry data had the poorest survival. Indeed, many of these patients had stage III-IV lung cancer and were too ill to perform PFT at time of diagnosis. However, we did not find any significant difference in survival between patients with and without COPD. The majority of our lung cancer patients with both
COPD and emphysema had moderate COPD, and due to the short survival time of lung cancer patients with advancedstage disease, neither COPD nor emphysema had a significant impact on survival in this study.

Other-NSCLC patients had poorer survival than those with adenocarcinoma, SCC, and SCLC, which is in agreement with previous knowledge, as the other histologic types of NSCLC have increased malignancy and a lower treatment effect. ${ }^{1,2,5}$ Survival was age-independent until 75 years of age, and we found weak significantly better survival in females compared to males. Lung cancer accounts for $25 \%$ of all cancer deaths among females, and this percentage continues to increase, possibly due to a lower decrease in smoking frequency among females. ${ }^{31}$ In contrast, lung cancer mortality is decreasing in males, although previous studies have shown that males generally smoke more pack-years than females. ${ }^{31}$

Respiratory failure affects the prognosis of COPD survival severely. The information on arterial blood gases in our study showed that lung cancer patients with severe hypoxemia had significantly poorer survival. Moreover, a majority of these patients had COPD. Hypercapnia predicted significantly poorer survival in patients with stage I lung cancer, but there were few patients in this group. A low $\mathrm{PaCO}_{2}$ level indicates hyperventilation provoked by the sensation of dyspnea caused by the severity of the lung cancer itself, and predicted poorer survival in patients with stage IV lung cancer in our study.

This study represents a time period immediately before 2011, when the Lean method was implemented as a clinical 
pathway facilitator in patients with lung cancer. After the introduction of the Lean method, the workup time for lung cancer patients decreased from a mean of 64 days to 16 days, and the median time from diagnosis to surgery went from 26.5 days to 15 days, ${ }^{33}$ both of which could lead to increased survival rates.

A previous study showed that there is an association between COPD and lung cancer, and that the combination of these two diseases leads to a worse outcome. It is reported that there are fewer thoracic surgeries performed in patients with COPD than in those without, and that PFT, cancer stage, and age at diagnosis are associated with the decision to go forward with surgery. Older lung cancer patients with COPD can be treated with chemotherapy and/or radiation therapy, but a systematic, comprehensive assessment of COPD at time of bronchoscopy allows us to implement the optimum management for lung cancer patients..$^{34,35}$ For example, patients with primary, stage I lung cancer who are ineligible for surgery due to COPD are now treated by stereotactic radiation therapy with curative intention, and thus achieve improved survival. ${ }^{36}$ EGFR-targeted therapy may also increase survival in some lung cancer patients with COPD. ${ }^{37}$

Coexistence of lung cancer and emphysema can be assessed by a CT scan. Indeed, low-dose CT scans of the chest as screening for lung cancer have reduced the number of lung cancer deaths significantly, but costs have to be reduced. ${ }^{25,37}$ Preventive interventions should focus on smoking cessation and screening for early diagnosis. ${ }^{4,37,38}$ Future screening programs should focus on those 60-74 years of age, smokers, identifying patients with COPD, and early detection of lung cancer based on low-dose CT scans of the chest. ${ }^{37}$

\section{Conclusion}

The observed prevalence of COPD was lower than that in previous studies. Neither COPD nor emphysema were significantly associated with lung cancer mortality. However, at an early lung cancer stage, diagnosis and grading of COPD may have the potential to improve treatment decision and prognosis.

\section{Acknowledgments}

The authors thank Inger Sperstad at the Clinical Research Center for preparing the data for scanning into the SPSS. We also thank Monica Linea Vold for performing part of the data registration. This work was funded by the Department of Clinical Medicine, UiT Arctic University of Norway. No writing assistance outside the authors listed was used in preparing this manuscript.

\section{Disclosure}

The authors report no conflicts of interest in this work.

\section{References}

1. Jemal A, Bray F, Center MM, Ferlay J, Ward E, Forman D. Global cancer statistics. CA Cancer J Clin. 2011;61:69-90.

2. Cancer. [webpage on the Internet]. World Health Organization. [cited February 2015]. Available from: http://www.who.int/mediacentre/ factsheets/fs297/en/. Accessed February 9, 2016.

3. Villeneuve PJ, Mao Y. Lifetime probability of developing lung cancer, by smoking status, Canada. Can J Public Health. 1994;85:385-388.

4. Peto R, Darby S, Deo H, Silcocks P, Whitley E, Doll R. Smoking, smoking cessation, and lung cancer in the UK since 1950: combination of national statistics with two case-control studies. BMJ. 2000;321: 323-329.

5. Alberg AJ, Ford JG, Samet JM. Epidemiology of lung cancer: ACCP Evidence-Based Clinical Practice Guidelines (2nd edition). Chest. 2007;132:29S-55S.

6. Midthun DE, Jett RJ. Lung tumors. In: Albert RK, Spiro SG, Jett JR, editors. Clinical Respiratory Medicine. 3rd ed. Philadelphia: Mosby Elsevier; 2008:605-631.

7. Global Strategy for Diagnosis, Management, and Prevention of COPD 2016. [webpage on the Internet]. Global Initiative for Chronic Obstructive Lung Disease. Available from: www.goldcopd.org/guidelines-globalstrategy-for-diagnosis-management.html. Accessed February 9, 2016.

8. Fletcher C, Peto R, Tinker C, Speizer FE. The Natural History of Chronic Bronchitis and Emphysema: An Eight-year Study of Early Chronic Obstructive Lung Disease in Working Men in London. New York: Oxford University Press; 1976.

9. El-Zein RA, Young RP, Hopkins RJ, Etzel CJ. Genetic predisposition to chronic obstructive pulmonary disease and/or lung cancer: important considerations when evaluating risk. Cancer Prev Res (Phila). 2012;5: $522-527$.

10. Takiguchi Y, Sekine I, Iwasawa S, Kurimoto R, Tatsumi K. Chronic obstructive pulmonary disease as a risk factor for lung cancer. World $J$ Clin Oncol. 2014;5:660-666.

11. Peek RM Jr, Mohla S, DuBois RN. Inflammation in the genesis and perpetuation of cancer: summary and recommendations from a National Cancer Institute-sponsored meeting. Cancer Res. 2005;65:8583-8586.

12. Brenner DR, McLaughlin JR, Hung RJ. Previous lung diseases and lung cancer risk: a systematic review and meta-analysis. PLoS One. 2011;6:e17479.

13. Turner MC, Chen Y, Krewski D, Calle EE, Thun MJ. Chronic obstructive pulmonary disease is associated with lung cancer mortality in a prospective study of never smokers. Am J Respir Crit Care Med. 2007; 176:285-290.

14. Young RP, Hopkins RJ, Christmas T, Black PN, Metcalf P, Gamble GD. COPD prevalence is increased in lung cancer, independent of age, sex and smoking history. Eur Respir J. 2009;34:380-386.

15. de Torres JP, Bastarrika G, Wisnivesky JP, et al. Assessing the relationship between lung cancer risk and emphysema detected on low-dose CT of the chest. Chest. 2007;132:1932-1938.

16. Powell HA, Iyen-Omofoman B, Baldwin DR, Hubbard RB, Tata LJ. Chronic obstructive pulmonary disease and risk of lung cancer: the importance of smoking and timing of diagnosis. J Thorac Oncol. 2013; $8: 6-11$.

17. American Thoracic Society. Chronic bronchitis, asthma and pulmonary emphysema: a statement by the Committee on Diagnostic Standards for Nontuberculous Respiratory Diseases. Am Rev Respir Dis. 1962;85:762-768.

18. Lindberg A, Jonsson AC, Rönmark E, Lundgren R, Larsson LG, Lundbäck B. Prevalence of chronic obstructive pulmonary disease to BTS, ERS, GOLD and ATS criteria in relation to doctor's diagnosis, symptoms, age, gender, and smoking habits. Respiration. 2005;72: 471-479. 
19. Smith BM, Pinto L, Ezer N, Sverzellati N, Muro S, Schwartzman K. Emphysema detected on computed tomography and risk of lung cancer: a systematic review and meta-analysis. Lung Cancer. 2012;77:58-63.

20. National Lung Screening Trial Research Team, Aberle DR, Adams AM, et al. Reduced lung-cancer mortality with low-dose computed tomographic screening. N Engl J Med. 2011;365:395-409.

21. Travis WD, Brambilla E, Noguchi M, et al. International Association for the Study of Lung Cancer/American Thoracic Society/European Respiratory Society international multidisciplinary classification of lung adenocarcinoma. J Thorac Oncol. 2011;6:244-285.

22. Mountain CF, Dresler CM. Regional lymph node classification for lung cancer staging. Chest. 1997;111:1718-1723.

23. Mountain CF. Revisions in the international system for staging lung cancer. Chest. 1997;111:1710-1717.

24. Detterbeck FC, Boffa DJ, Tanoue LT. The new lung cancer staging system. Chest. 2009;136:260-271.

25. Wilson DO, Leader JK, Fuhrman CR, Reilly JJ, Sciurba FC, Weissfeld JL. Quantitative computed tomography analysis, airflow obstruction, and lung cancer in the Pittsburg Lung Screening Study. J Thorac Oncol. 2011;6:1200-1205.

26. National Emphysema Treatment Trial Research Group. Patients at high risk of death after lung-volume-reduction surgery. $N$ Engl J Med. 2001;345:1075-1083.

27. Aalen OO, Borgan O, Gjessing HK. Survival and Event History Analysis: A Process Point of View. New York: Springer; 2008.

28. Therneau T. Survival: survival analysis. 2012. Available from: https:// cran.r-project.org/web/packages/survival/index.html. Accessed February 11, 2016.

29. R Foundation. The R Project for statistical computing. Available from: https://www.r-project.org. Accessed February 11, 2016.
30. Gjessing HK. invGauss: Threshold regression that fits the (randomized drift) inverse Gaussian distribution to survival data. 2014. Available from: http://cran.r-project.org/package=invGauss. Accessed February 11, 2016.

31. Loganathan RS, Stover DE, Shi W, Venkatraman E. Prevalence of COPD in women compared to men around the time of diagnosis of primary lung cancer. Chest 2006;129:1305-1312.

32. Wasswa-Kintu S, Gan WQ, Man SF, Pare PD, Sin DD. Relationship between reduced forced expiratory volume in one second and the risk of lung cancer: a systematic review and meta-analysis. Thorax. 2005;60: $570-575$.

33. Aasebø U, Strøm HH, Postmyr M. The Lean method as a clinical pathway facilitator in patients with lung cancer. Clin Respir J. 2012;6: 169-174.

34. Hashimoto N, Matsuzaki A, Okada Y, et al. Clinical impact of prevalence and severity of COPD on the decision-making process for therapeutic management of lung cancer patients. BMC Pulm Med. 2014; $14: 14$.

35. Brunelli A, Charloux A, Bolliger CT, et al. ERS/ESTS clinical guidelines on fitness for radical therapy in lung cancer patients (surgery and chemo-radiotherapy). Eur Respir J. 2009;34:17-41.

36. Palma D, Lagerwaard F, Rodrigues G, Haasbeek C, Senan S. Curative treatment of stage I non-small-cell lung cancer in patients with severe COPD: stereotactic radiotherapy outcomes and systematic review. Int $J$ Radiat Oncol Biol Phys. 2012;82:1149-1156.

37. Field JK, Hansell DM, Duffy SW, Baldwin DR. CT screening for lung cancer: countdown to implementation. Lancet Oncol. 2013;14: e591-e600.

38. Godtfredsen NS, Prescott E, Osler M. Effect of smoking reduction on lung cancer risk. JAMA. 2005;294:1505-1510. 


\section{Supplementary material}

Table SI Survival of primary lung cancer of all 174 patients diagnosed at University Hospital of North Norway 2008-20I0

\begin{tabular}{|c|c|c|c|c|c|c|c|c|c|c|}
\hline ID & Sex & $\begin{array}{l}\text { Age-group, } \\
\text { years }\end{array}$ & COPD diagnosis & Emph & $\begin{array}{l}\mathrm{PaO}_{2}, \\
\text { range }\end{array}$ & $\begin{array}{l}\mathrm{PaCO}_{2}, \\
\text { range }\end{array}$ & Cancer & Stage & Time & D \\
\hline I & $\mathrm{F}$ & $30-74$ & No COPD & 0 & $10-15$ & $3-4.9$ & Ad-NSCLC & III & 377 & 1 \\
\hline 2 & $M$ & $30-74$ & Missing - spirometry & 0 & NA & NA & $S C C-N S C L C$ & IV & 340 & I \\
\hline 3 & $M$ & $30-74$ & No COPD & I & $10-15$ & $3-4.9$ & SCLC & IV & 157 & I \\
\hline 4 & $M$ & $30-74$ & No COPD & 0 & $10-15$ & $3-4.9$ & SCLC & IV & 547 & 1 \\
\hline 5 & $M$ & $30-74$ & No COPD & 0 & $10-15$ & $5-5.9$ & Ad-NSCLC & IV & 2,067 & I \\
\hline 6 & M & $30-74$ & No COPD & 0 & $10-15$ & $5-5.9$ & SCC - NSCLC & III & 1,243 & 1 \\
\hline 7 & M & $30-74$ & No COPD & 0 & $10-15$ & $3-4.9$ & SCC - NSCLC & III & 279 & 1 \\
\hline 8 & M & $30-74$ & Known COPD & 1 & $4-8.4$ & $5-5.9$ & SCLC & III & 365 & 1 \\
\hline 9 & $\mathrm{~F}$ & $75-91$ & Known COPD & 0 & $10-15$ & $5-5.9$ & SCLC & III & 620 & I \\
\hline 10 & $M$ & $75-91$ & Known COPD & 0 & $8.5-9.9$ & $3-4.9$ & SCLC & IV & 16 & I \\
\hline II & $\mathrm{F}$ & $30-74$ & No COPD & 0 & $10-15$ & $3-4.9$ & Other - NSCLC & I & 803 & 1 \\
\hline 12 & $M$ & $75-91$ & No COPD & 1 & $4-8.4$ & $5-5.9$ & SCLC & IV & 77 & 1 \\
\hline 13 & $\mathrm{~F}$ & $30-74$ & No COPD & 0 & $10-15$ & $5-5.9$ & Ad-NSCLC & I & 353 & 1 \\
\hline 14 & $M$ & $30-74$ & No COPD & I & $10-15$ & $3-4.9$ & SCLC & IV & 188 & I \\
\hline 15 & $M$ & $30-74$ & No COPD & 0 & $10-15$ & $5-5.9$ & SCC - NSCLC & ॥ & 289 & I \\
\hline 16 & $\mathrm{~F}$ & $30-74$ & No COPD & 1 & $4-8.4$ & $6-10$ & SCC - NSCLC & III & 2,175 & 1 \\
\hline 17 & $M$ & $30-74$ & Missing - spirometry & 0 & $10-15$ & $5-5.9$ & SCC - NSCLC & IV & 104 & I \\
\hline 18 & M & $75-91$ & Missing - spirometry & 1 & $4-8.4$ & $3-4.9$ & NA & IV & 10 & 1 \\
\hline 19 & M & $30-74$ & No COPD & 0 & $10-15$ & $3-4.9$ & Other - NSCLC & IV & 41 & I \\
\hline 20 & $M$ & $30-74$ & No COPD & 0 & $10-15$ & $3-4.9$ & SCLC & NA & 155 & 1 \\
\hline 21 & $\mathrm{~F}$ & $30-74$ & No COPD & 0 & $8.5-9.9$ & $5-5.9$ & Ad-NSCLC & IV & 245 & 1 \\
\hline 22 & $M$ & $30-74$ & No COPD & 0 & $10-15$ & $5-5.9$ & SCC - NSCLC & IV & 116 & 1 \\
\hline 23 & $\mathrm{~F}$ & $30-74$ & No COPD & 1 & $10-15$ & $3-4.9$ & Ad-NSCLC & IV & 131 & 1 \\
\hline 24 & M & $30-74$ & Known COPD & 1 & $4-8.4$ & $3-4.9$ & Ad-NSCLC & IV & 287 & 1 \\
\hline 25 & $M$ & $75-91$ & No COPD & 1 & $10-15$ & $5-5.9$ & SCC - NSCLC & IV & 45 & 1 \\
\hline 26 & $\mathrm{~F}$ & $30-74$ & No COPD & 0 & $10-15$ & $3-4.9$ & Ad-NSCLC & III & $\mathrm{I}, 787$ & I \\
\hline 27 & $M$ & $75-91$ & Undiagnosed COPD & 1 & $8.5-9.9$ & $5-5.9$ & SCC - NSCLC & IV & 52 & 1 \\
\hline 28 & $\mathrm{~F}$ & $30-74$ & Missing - spirometry & 1 & $4-8.4$ & $5-5.9$ & SCC - NSCLC & IV & 54 & I \\
\hline 29 & $M$ & $30-74$ & No COPD & 0 & $10-15$ & $3-4.9$ & NA & IV & 162 & 1 \\
\hline 30 & $M$ & $75-91$ & Known COPD & 1 & $4-8.4$ & $6-10$ & SCC - NSCLC & IV & 319 & 1 \\
\hline 31 & $\mathrm{~F}$ & $30-74$ & No COPD & 0 & $10-15$ & $3-4.9$ & Ad-NSCLC & IV & 561 & I \\
\hline 32 & $M$ & $30-74$ & Known COPD & 1 & $4-8.4$ & $5-5.9$ & SCLC & IV & I,076 & I \\
\hline 33 & $M$ & $30-74$ & Missing - spirometry & 1 & NA & NA & SCC - NSCLC & III & 91 & 1 \\
\hline 34 & $M$ & $75-91$ & Known COPD & 0 & $10-15$ & $5-5.9$ & SCLC & III & 27 & 1 \\
\hline 35 & $M$ & 75-9| & No COPD & 0 & $10-15$ & $3-4.9$ & SCLC & IV & 7 & 1 \\
\hline 36 & $\mathrm{~F}$ & $30-74$ & No COPD & 0 & $4-8.4$ & $5-5.9$ & Ad-NSCLC & IV & 76 & 1 \\
\hline 37 & $\mathrm{~F}$ & $75-91$ & No COPD & 0 & $10-15$ & $3-4.9$ & Ad-NSCLC & II & 192 & 1 \\
\hline 38 & $\mathrm{~F}$ & $75-91$ & No COPD & I & $10-15$ & $3-4.9$ & $S C C-N S C L C$ & ॥ & 370 & I \\
\hline 39 & $\mathrm{~F}$ & $30-74$ & No COPD & 1 & $8.5-9.9$ & $6-10$ & Ad-NSCLC & I & 377 & 1 \\
\hline 40 & M & 75-9| & Missing - spirometry & 0 & $10-15$ & $5-5.9$ & SCC - NSCLC & IV & 36 & 1 \\
\hline 41 & $\mathrm{~F}$ & $30-74$ & Known COPD & 0 & $10-15$ & $5-5.9$ & Other - NSCLC & III & 33 & 1 \\
\hline 42 & M & $30-74$ & Known COPD & 0 & $4-8.4$ & $5-5.9$ & SCLC & III & $|, 46|$ & 1 \\
\hline 43 & $M$ & $30-74$ & No COPD & I & $10-15$ & $3-4.9$ & Other - NSCLC & IV & $14 \mid$ & I \\
\hline 44 & $\mathrm{~F}$ & $30-74$ & Missing - spirometry & I & NA & NA & SCC - NSCLC & III & 28 & 1 \\
\hline 45 & $\mathrm{~F}$ & $30-74$ & No COPD & 0 & $8.5-9.9$ & $5-5.9$ & Ad-NSCLC & IV & 576 & 1 \\
\hline 46 & $\mathrm{~F}$ & $30-74$ & Missing - spirometry & 1 & $4-8.4$ & $5-5.9$ & SCLC & IV & 130 & 1 \\
\hline 47 & M & $30-74$ & Known COPD & 1 & $4-8.4$ & $5-5.9$ & Ad-NSCLC & III & 38 & 1 \\
\hline 48 & $\mathrm{~F}$ & $75-91$ & No COPD & 1 & $10-15$ & $3-4.9$ & Ad-NSCLC & IV & 44 & 1 \\
\hline 49 & $M$ & $30-74$ & No COPD & I & $10-15$ & $5-5.9$ & Ad-NSCLC & I & 2,298 & 0 \\
\hline 50 & $M$ & $30-74$ & No COPD & 0 & $10-15$ & $6-10$ & Ad-NSCLC & III & 132 & I \\
\hline 51 & $M$ & $30-74$ & Undiagnosed COPD & 1 & $8.5-9.9$ & $5-5.9$ & Ad-NSCLC & III & 83 & 1 \\
\hline 52 & $M$ & $30-74$ & No COPD & 1 & $10-15$ & $3-4.9$ & Ad-NSCLC & III & 204 & 1 \\
\hline 53 & M & $30-74$ & No COPD & 1 & $8.5-9.9$ & $5-5.9$ & SCLC & IV & 166 & 1 \\
\hline 54 & $\mathrm{~F}$ & $75-91$ & Undiagnosed COPD & 0 & $8.5-9.9$ & $6-10$ & SCC - NSCLC & II & 50 & 1 \\
\hline 55 & $\mathrm{~F}$ & $30-74$ & No COPD & 0 & $10-15$ & $5-5.9$ & SCLC & IV & 175 & I \\
\hline
\end{tabular}


Table SI (Continued)

\begin{tabular}{|c|c|c|c|c|c|c|c|c|c|c|}
\hline ID & Sex & $\begin{array}{l}\text { Age-group, } \\
\text { years }\end{array}$ & COPD diagnosis & Emph & $\begin{array}{l}\mathrm{PaO}_{2}, \\
\text { range }\end{array}$ & $\begin{array}{l}\mathrm{PaCO}_{2}, \\
\text { range }\end{array}$ & Cancer & Stage & Time & D \\
\hline 56 & $M$ & $75-91$ & No COPD & 1 & $8.5-9.9$ & $3-4.9$ & SCC - NSCLC & III & 28 & 1 \\
\hline 57 & $M$ & $30-74$ & Undiagnosed COPD & I & $10-15$ & $5-5.9$ & SCC - NSCLC & I & 2,155 & I \\
\hline 58 & $M$ & $30-74$ & Known COPD & 0 & $10-15$ & $3-4.9$ & Other - NSCLC & IV & 168 & I \\
\hline 59 & $\mathrm{~F}$ & $30-74$ & Missing - spirometry & 0 & $4-8.4$ & $3-4.9$ & Ad-NSCLC & IV & 2 & I \\
\hline 60 & $M$ & $75-91$ & Known COPD & 0 & $10-15$ & $5-5.9$ & $S C C-N S C L C$ & III & 415 & I \\
\hline 61 & $M$ & $30-74$ & No COPD & 0 & $10-15$ & $5-5.9$ & Ad-NSCLC & IV & 917 & I \\
\hline 62 & $M$ & $30-74$ & Known COPD & I & $10-15$ & $5-5.9$ & SCC - NSCLC & III & 475 & I \\
\hline 63 & $\mathrm{~F}$ & $30-74$ & No COPD & 0 & $8.5-9.9$ & $5-5.9$ & SCLC & IV & I,485 & I \\
\hline 64 & $M$ & $30-74$ & Known COPD & I & $4-8.4$ & $3-4.9$ & SCLC & III & 13 & I \\
\hline 65 & $M$ & $75-91$ & Undiagnosed COPD & I & $8.5-9.9$ & $3-4.9$ & SCC - NSCLC & III & 460 & I \\
\hline 66 & $\mathrm{~F}$ & $30-74$ & No COPD & 0 & NA & NA & Ad-NSCLC & III & 698 & I \\
\hline 67 & $M$ & $30-74$ & Known COPD & I & $4-8.4$ & $5-5.9$ & Ad-NSCLC & IV & 226 & I \\
\hline 68 & $M$ & $30-74$ & No COPD & 0 & $8.5-9.9$ & $5-5.9$ & Ad-NSCLC & IV & 184 & I \\
\hline 69 & $\mathrm{~F}$ & $30-74$ & No COPD & I & $10-15$ & $5-5.9$ & Ad-NSCLC & I & 2,196 & 0 \\
\hline 70 & $\mathrm{~F}$ & $30-74$ & No COPD & 0 & $10-15$ & $5-5.9$ & Ad-NSCLC & III & 265 & I \\
\hline 7I & $\mathrm{F}$ & $30-74$ & No COPD & I & $8.5-9.9$ & $3-4.9$ & $S C C-N S C L C$ & II & 2,189 & 0 \\
\hline 72 & $M$ & $30-74$ & No COPD & I & $10-15$ & $3-4.9$ & SCC - NSCLC & III & 287 & I \\
\hline 73 & M & $30-74$ & Known COPD & I & $8.5-9.9$ & $5-5.9$ & SCLC & IV & 492 & I \\
\hline 74 & $M$ & $30-74$ & Missing - spirometry & 0 & $8.5-9.9$ & $6-10$ & $S C C-N S C L C$ & IV & 501 & I \\
\hline 75 & $\mathrm{~F}$ & $30-74$ & No COPD & 0 & $8.5-9.9$ & $5-5.9$ & Ad-NSCLC & $\|$ & ।,758 & I \\
\hline 76 & $M$ & $30-74$ & No COPD & 0 & $10-15$ & $5-5.9$ & $S C C-N S C L C$ & III & 432 & I \\
\hline 77 & $\mathrm{~F}$ & $30-74$ & No COPD & 0 & $10-15$ & $5-5.9$ & SCLC & III & 2,142 & 0 \\
\hline 78 & $M$ & $30-74$ & No COPD & I & NA & NA & SCC - NSCLC & ॥ & $2,|4|$ & 0 \\
\hline 79 & $M$ & $30-74$ & No COPD & I & $8.5-9.9$ & $3-4.9$ & SCLC & IV & 18 & I \\
\hline 80 & $\mathrm{~F}$ & $30-74$ & Missing - spirometry & 0 & $10-15$ & $3-4.9$ & SCLC & IV & 19 & I \\
\hline 81 & $M$ & $75-91$ & Missing - spirometry & 0 & NA & NA & SCLC & IV & 35 & I \\
\hline 82 & $\mathrm{~F}$ & $30-74$ & Missing - spirometry & 0 & $8.5-9.9$ & $3-4.9$ & $S C C-N S C L C$ & IV & 135 & I \\
\hline 83 & $\mathrm{~F}$ & $30-74$ & Known COPD & I & $4-8.4$ & $3-4.9$ & SCLC & IV & 111 & I \\
\hline 84 & $\mathrm{~F}$ & $30-74$ & Known COPD & 0 & NA & NA & SCLC & IV & 58 & I \\
\hline 85 & $\mathrm{~F}$ & $30-74$ & Undiagnosed COPD & I & $10-15$ & $5-5.9$ & SCC - NSCLC & III & 2,114 & 0 \\
\hline 86 & $\mathrm{~F}$ & $30-74$ & No COPD & 0 & NA & NA & Ad-NSCLC & III & 254 & I \\
\hline 87 & $M$ & $75-91$ & Missing - spirometry & I & NA & NA & SCLC & IV & 35 & I \\
\hline 88 & $\mathrm{~F}$ & $75-91$ & No COPD & 0 & $4-8.4$ & $3-4.9$ & Ad-NSCLC & IV & 18 & I \\
\hline 89 & $M$ & $75-91$ & Known COPD & I & $10-15$ & $3-4.9$ & SCLC & $\|$ & 417 & I \\
\hline 90 & $M$ & $30-74$ & Known COPD & I & $10-15$ & $5-5.9$ & Ad-NSCLC & 1 & 249 & I \\
\hline 91 & $\mathrm{~F}$ & $30-74$ & Known COPD & I & $4-8.4$ & $6-10$ & Ad-NSCLC & III & 630 & I \\
\hline 92 & $\mathrm{~F}$ & $30-74$ & Undiagnosed COPD & 0 & $10-15$ & $3-4.9$ & Ad-NSCLC & IV & 22 & I \\
\hline 93 & $M$ & $30-74$ & No COPD & I & $10-15$ & $5-5.9$ & Ad-NSCLC & III & 728 & I \\
\hline 94 & $M$ & $75-91$ & No COPD & I & $8.5-9.9$ & $3-4.9$ & NA & III & $17 \mid$ & I \\
\hline 95 & $\mathrm{~F}$ & $30-74$ & Known COPD & 0 & $8.5-9.9$ & $5-5.9$ & SCLC & IV & 512 & I \\
\hline 96 & $\mathrm{~F}$ & $30-74$ & Missing - spirometry & I & NA & NA & Ad-NSCLC & IV & 455 & I \\
\hline 97 & $M$ & $30-74$ & Known COPD & 0 & $10-15$ & $5-5.9$ & SCLC & III & 441 & I \\
\hline 98 & $\mathrm{~F}$ & $75-91$ & Known COPD & I & $4-8.4$ & $5-5.9$ & $S C C-N S C L C$ & 1 & 1,329 & I \\
\hline 99 & $M$ & $75-91$ & Known COPD & I & $4-8.4$ & $3-4.9$ & SCC - NSCLC & III & 163 & I \\
\hline 100 & $\mathrm{~F}$ & $30-74$ & No COPD & 0 & $10-15$ & $3-4.9$ & SCLC & 1 & 1,902 & 0 \\
\hline 101 & $\mathrm{~F}$ & $75-91$ & No COPD & 0 & $10-15$ & $3-4.9$ & Ad-NSCLC & IV & 537 & I \\
\hline 102 & $\mathrm{~F}$ & $75-9 \mid$ & No COPD & 0 & $8.5-9.9$ & $5-5.9$ & NA & IV & 345 & I \\
\hline 103 & $\mathrm{~F}$ & $75-91$ & Undiagnosed COPD & 0 & $4-8.4$ & $5-5.9$ & Ad-NSCLC & IV & 159 & I \\
\hline 104 & $M$ & $75-91$ & Missing - spirometry & 0 & NA & NA & NA & IV & 14 & I \\
\hline 105 & $M$ & $30-74$ & No COPD & 0 & $8.5-9.9$ & $5-5.9$ & SCLC & I & I,983 & 0 \\
\hline 106 & M & $75-91$ & Known COPD & I & $8.5-9.9$ & $5-5.9$ & SCC - NSCLC & $\|$ & 526 & I \\
\hline 107 & $M$ & $30-74$ & Missing - spirometry & I & NA & NA & Ad-NSCLC & IV & 222 & I \\
\hline 108 & $\mathrm{~F}$ & $75-91$ & Known COPD & I & NA & NA & Ad-NSCLC & IV & 82 & I \\
\hline 109 & $M$ & $75-91$ & Known COPD & 0 & $8.5-9.9$ & $5-5.9$ & Ad-NSCLC & IV & 168 & I \\
\hline 110 & $\mathrm{~F}$ & $75-91$ & Known COPD & I & $4-8.4$ & $5-5.9$ & SCC - NSCLC & III & 197 & I \\
\hline 111 & $M$ & $30-74$ & No COPD & 0 & NA & NA & Ad-NSCLC & IV & $1,4 \mid 2$ & I \\
\hline
\end{tabular}

(Continued) 
Table SI (Continued)

\begin{tabular}{|c|c|c|c|c|c|c|c|c|c|c|}
\hline ID & Sex & $\begin{array}{l}\text { Age-group, } \\
\text { years }\end{array}$ & COPD diagnosis & Emph & $\begin{array}{l}\mathrm{PaO}_{2}, \\
\text { range }\end{array}$ & $\begin{array}{l}\mathrm{PaCO}_{2}, \\
\text { range }\end{array}$ & Cancer & Stage & Time & D \\
\hline 112 & $\mathrm{~F}$ & $30-74$ & No COPD & 0 & $10-15$ & $5-5.9$ & SCC - NSCLC & IV & 1,092 & 1 \\
\hline 113 & M & $75-91$ & No COPD & I & $8.5-9.9$ & $3-4.9$ & SCC - NSCLC & ॥ & 195 & I \\
\hline 114 & M & $30-74$ & Known COPD & 1 & $10-15$ & $5-5.9$ & SCLC & IV & 990 & I \\
\hline 115 & $\mathrm{~F}$ & $75-91$ & No COPD & I & $10-15$ & $5-5.9$ & Ad-NSCLC & 1 & $\mathrm{I}, 254$ & I \\
\hline 116 & M & $30-74$ & No COPD & I & $8.5-9.9$ & $3-4.9$ & SCC - NSCLC & III & 789 & I \\
\hline 117 & $\mathrm{~F}$ & $30-74$ & Undiagnosed COPD & I & $10-15$ & $5-5.9$ & Ad-NSCLC & II & 1,892 & 0 \\
\hline 118 & $\mathrm{~F}$ & $75-91$ & Known COPD & 1 & $8.5-9.9$ & $3-4.9$ & SCLC & 1 & 921 & I \\
\hline 119 & $\mathrm{~F}$ & $30-74$ & Known COPD & 1 & $4-8.4$ & $5-5.9$ & SCC - NSCLC & III & 618 & I \\
\hline 120 & $M$ & $30-74$ & Undiagnosed COPD & 0 & $10-15$ & $5-5.9$ & SCLC & I & I,875 & 0 \\
\hline 121 & $\mathrm{~F}$ & $30-74$ & Known COPD & I & $8.5-9.9$ & $3-4.9$ & SCC - NSCLC & III & 69 & I \\
\hline 122 & $M$ & $30-74$ & Undiagnosed COPD & I & $4-8.4$ & $3-4.9$ & Ad-NSCLC & IV & 16 & I \\
\hline 123 & $\mathrm{~F}$ & $30-74$ & No COPD & I & $10-15$ & $3-4.9$ & Ad-NSCLC & IV & 181 & I \\
\hline 124 & M & $75-91$ & Known COPD & 1 & $10-15$ & $3-4.9$ & SCC - NSCLC & IV & 81 & I \\
\hline 125 & M & $30-74$ & Known COPD & 1 & $10-15$ & $3-4.9$ & Ad-NSCLC & III & 195 & I \\
\hline 126 & M & $30-74$ & No COPD & 1 & $10-15$ & $3-4.9$ & SCC - NSCLC & III & 471 & I \\
\hline 127 & $\mathrm{~F}$ & $30-74$ & Known COPD & I & $8.5-9.9$ & $6-10$ & $S C C-N S C L C$ & III & 92 & I \\
\hline 128 & $M$ & $30-74$ & No COPD & I & $8.5-9.9$ & $3-4.9$ & SCLC & IV & 3 & I \\
\hline 129 & M & $30-74$ & No COPD & 1 & $8.5-9.9$ & $5-5.9$ & SCC - NSCLC & IV & 153 & I \\
\hline 130 & M & $30-74$ & Known COPD & 1 & $10-15$ & $6-10$ & SCC - NSCLC & 1 & 555 & I \\
\hline$|3|$ & M & $30-74$ & Known COPD & 1 & $10-15$ & $3-4.9$ & Ad-NSCLC & III & 148 & I \\
\hline 132 & $M$ & $75-91$ & No COPD & I & NA & NA & Ad-NSCLC & 1 & $\mathrm{I}, 847$ & 0 \\
\hline 133 & $M$ & $30-74$ & Known COPD & I & $10-15$ & $5-5.9$ & SCC - NSCLC & III & 417 & I \\
\hline 134 & $M$ & $30-74$ & No COPD & I & $10-15$ & $5-5.9$ & $S C C-N S C L C$ & 1 & 1,840 & 0 \\
\hline 135 & M & $30-74$ & No COPD & 1 & $10-15$ & $5-5.9$ & SCC - NSCLC & II & $\mathrm{I}, 875$ & 0 \\
\hline 136 & $\mathrm{~F}$ & $30-74$ & No COPD & 1 & NA & NA & Ad-NSCLC & III & 776 & I \\
\hline 137 & M & $30-74$ & No COPD & I & $4-8.4$ & $3-4.9$ & Ad-NSCLC & IV & 14 & I \\
\hline 138 & $\mathrm{~F}$ & $30-74$ & Undiagnosed COPD & 1 & $10-15$ & $3-4.9$ & SCLC & IV & 437 & I \\
\hline 139 & $\mathrm{~F}$ & $30-74$ & Known COPD & I & $10-15$ & $3-4.9$ & Ad-NSCLC & III & 1,818 & 0 \\
\hline 140 & $M$ & $75-91$ & No COPD & 1 & $8.5-9.9$ & $5-5.9$ & SCLC & III & 924 & I \\
\hline$|4|$ & $M$ & $75-91$ & Known COPD & 1 & $10-15$ & $5-5.9$ & SCC - NSCLC & 1 & $\mathrm{I}, 797$ & 0 \\
\hline 142 & M & $30-74$ & Known COPD & 0 & $8.5-9.9$ & $3-4.9$ & SCC - NSCLC & IV & 214 & I \\
\hline 143 & $\mathrm{~F}$ & $30-74$ & Known COPD & I & $8.5-9.9$ & $5-5.9$ & SCC - NSCLC & 1 & $\mathrm{I}, 744$ & 0 \\
\hline 144 & $M$ & 75-91 & Missing - spirometry & I & $8.5-9.9$ & $5-5.9$ & $S C C-N S C L C$ & III & 701 & I \\
\hline 145 & $M$ & $30-74$ & No COPD & 0 & $10-15$ & $3-4.9$ & Ad-NSCLC & IV & 278 & I \\
\hline 146 & $M$ & $75-91$ & Known COPD & I & $10-15$ & $3-4.9$ & Ad-NSCLC & IV & 397 & I \\
\hline 147 & M & $30-74$ & No COPD & 1 & $10-15$ & $5-5.9$ & SCLC & III & 176 & I \\
\hline 148 & M & $30-74$ & Missing - spirometry & 1 & $4-8.4$ & $5-5.9$ & Ad-NSCLC & IV & 37 & I \\
\hline 149 & M & $30-74$ & Known COPD & 0 & $10-15$ & $5-5.9$ & Ad-NSCLC & IV & 290 & I \\
\hline 150 & $\mathrm{~F}$ & $30-74$ & Known COPD & 1 & $8.5-9.9$ & $5-5.9$ & NA & III & 249 & I \\
\hline 151 & $M$ & $30-74$ & Missing - spirometry & I & NA & NA & Ad-NSCLC & IV & $|3|$ & I \\
\hline 152 & $\mathrm{~F}$ & $30-74$ & No COPD & I & NA & NA & SCLC & IV & 288 & I \\
\hline 153 & $M$ & $75-91$ & Known COPD & 1 & $10-15$ & $6-10$ & SCC - NSCLC & 1 & 98 & I \\
\hline 154 & $\mathrm{~F}$ & $30-74$ & No COPD & 0 & $10-15$ & $5-5.9$ & Ad-NSCLC & III & $\mathrm{I}, 747$ & 0 \\
\hline 155 & $M$ & $30-74$ & Known COPD & I & $8.5-9.9$ & $5-5.9$ & SCC - NSCLC & III & 741 & I \\
\hline 156 & $M$ & 75-91 & Missing - spirometry & I & NA & NA & SCLC & IV & 184 & I \\
\hline 157 & $\mathrm{~F}$ & $30-74$ & No COPD & I & $8.5-9.9$ & $5-5.9$ & SCLC & IV & 398 & I \\
\hline 158 & M & $30-74$ & No COPD & 0 & $10-15$ & $5-5.9$ & SCLC & IV & 449 & I \\
\hline 159 & M & $30-74$ & No COPD & 0 & $10-15$ & $3-4.9$ & Ad-NSCLC & ॥ & I,437 & I \\
\hline 160 & $\mathrm{~F}$ & $30-74$ & No COPD & 0 & $10-15$ & $3-4.9$ & Ad-NSCLC & IV & 166 & I \\
\hline 161 & M & $30-74$ & No COPD & 1 & $8.5-9.9$ & $3-4.9$ & Ad-NSCLC & IV & 141 & I \\
\hline 162 & M & $30-74$ & No COPD & 0 & $10-15$ & $3-4.9$ & SCC - NSCLC & III & $\mathrm{I}, 00 \mathrm{I}$ & I \\
\hline 163 & $\mathrm{~F}$ & $30-74$ & Missing - spirometry & I & $10-15$ & $5-5.9$ & SCLC & IV & 181 & I \\
\hline 164 & $\mathrm{~F}$ & $75-91$ & Known COPD & 1 & $10-15$ & $5-5.9$ & Ad-NSCLC & ॥ & 335 & I \\
\hline 165 & $\mathrm{~F}$ & $30-74$ & Missing - spirometry & 0 & NA & NA & SCC - NSCLC & IV & 236 & I \\
\hline 166 & $\mathrm{~F}$ & $75-91$ & Known COPD & I & $8.5-9.9$ & $5-5.9$ & Other - NSCLC & IV & 68 & I \\
\hline 167 & $M$ & $30-74$ & Known COPD & 1 & $8.5-9.9$ & $6-10$ & Ad-NSCLC & IV & 9 & I \\
\hline
\end{tabular}


Table SI (Continued)

\begin{tabular}{|c|c|c|c|c|c|c|c|c|c|c|}
\hline ID & Sex & $\begin{array}{l}\text { Age-group, } \\
\text { years }\end{array}$ & COPD diagnosis & Emph & $\begin{array}{l}\mathrm{PaO}_{2} \text {, } \\
\text { range }\end{array}$ & $\begin{array}{l}\mathrm{PaCO}_{2}, \\
\text { range }\end{array}$ & Cancer & Stage & Time & D \\
\hline 168 & $M$ & $30-74$ & Known COPD & 1 & $4-8.4$ & $5-5.9$ & SCLC & I & 445 & I \\
\hline 169 & $\mathrm{~F}$ & $30-74$ & No COPD & 0 & NA & NA & SCLC & III & 514 & I \\
\hline 170 & $\mathrm{~F}$ & $30-74$ & Known COPD & 0 & NA & NA & SCLC & IV & 333 & I \\
\hline 171 & $\mathrm{~F}$ & $30-74$ & Known COPD & 1 & $10-15$ & $3-4.9$ & Ad-NSCLC & II & 243 & I \\
\hline 172 & $\mathrm{~F}$ & $30-74$ & Known COPD & I & $4-8.4$ & $5-5.9$ & SCLC & IV & 244 & I \\
\hline 173 & $\mathrm{~F}$ & $30-74$ & No COPD & 1 & $10-15$ & $5-5.9$ & SCC - NSCLC & III & 632 & I \\
\hline 174 & $M$ & $30-74$ & Missing - spirometry & I & NA & NA & Ad-NSCLC & IV & 57 & I \\
\hline
\end{tabular}

Notes: Time represents survival time (days) from diagnosis of primary lung cancer; $D$ represents a censoring variable ( $\mathrm{I}$ if dead, 0 if alive at the end of the study period); $\mathrm{PaO}_{2}$ and $\mathrm{PaCO}_{2}$ in $\mathrm{kPa}$. Patients with missing data were categorized as "missing - spirometry".

Abbreviations: Ad-NSCLC, adenocarcinoma non-small-cell lung cancer; Emph, emphysema; F, female; M, male; NA, not available; $\mathrm{PaO}_{2}$, partial arterial oxygen pressure; SCC, squamous cell carcinoma; SCLC, small-cell lung cancer; $\mathrm{PaCO}_{2}$, partial arterial carbon dioxide pressure.

\section{Publish your work in this journal}

The International Journal of COPD is an international, peer-reviewed journal of therapeutics and pharmacology focusing on concise rapid reporting of clinical studies and reviews in COPD. Special focus is given to the pathophysiological processes underlying the disease, intervention programs, patient focused education, and self management protocols.
This journal is indexed on PubMed Central, MedLine and CAS. The manuscript management system is completely online and includes a very quick and fair peer-review system, which is all easy to use. Visit $\mathrm{http} / / / \mathrm{www}$.dovepress.com/testimonials.php to read real quotes from published authors. 